\title{
A Prickly Subject: Apoptotic Regulation by Hedgehog Morphogens
}

\author{
Mark Ditzel* \\ Institute of Genetics and Molecular Medicine, Edinburgh CRUK Research Centre, Cancer Biology, Crewe Road South, \\ Edinburgh EH4 $2 X R, U K$
}

\begin{abstract}
Morphogens, as intercellular signalling proteins, provide a non-cell-autonomous mechanism to impart positional information to cells and govern essential cellular processes such as apoptosis. Individual morphogen pathways utilise diverse strategies to regulate the assembly and activity of the pro-apoptotic multi-protein complexes - namely the apoptosome and the death-inducing signalling complex (DISC). This review aims to highlight the apoptotic regulatory mechanisms utilised by the Hedgehog $(\mathrm{HH})$ morphogen pathway - with particular emphasis on a novel Caspase-9 activating complex and the utilisation of a pro-apoptotic autocrine-signalling loop.
\end{abstract}

Keywords: Hedgehog, apoptosis, BMP, dependesome, patched, smoothened, morphogen.

\section{INTRODUCTION}

Apoptosis and morphogen signalling exhibit an intimate relationship. Both are essential for creating, and subsequently maintaining, adult animals, while aberrations in their activities are detrimental. At a functional level apoptosis can promote morphogen expression [1] and morphogen signalling can both promote or suppress apoptosis. An ability to modulate apoptotic and cell-survival pathways places them as key regulators of life and death. Although the majority of research has highlighted morphogens' roles in co-ordinating proliferation and differentiation in organismal development, more recent efforts have begun to identify the complex molecular mechanisms associated with morphogen-mediated apoptotic regulation.

\section{Apoptosis}

The majority of apoptosis occurring throughout development removes unnecessary, but otherwise normal cells [2], while apoptosis in the adult primarily removes damaged, defective [3] or infected cells [4]. Hence, cell death is initiated in response to a large number of different developmental cues and cellular insults. Distinct intrinsic or extrinsic cellular signalling pathways are activated in response to molecular instructions or stress signals received from the cells' interior or exterior, respectively. The intrinsic pathway is predominantly activated in response to cellautonomous apoptotic signals generated from within the cell [5] (e.g., DNA damage, anoxia and oncogene-activation). In contrast the extrinsic pathway is activated in response to recognition of extracellular ligands by cell-surface receptors (e.g., Fas [6]). In this manner neighbouring or infiltrating cells produce ligands to induce the death of another cell. However, cells may also autonomously produce, release and react to their own extrinsic death signals [7]. Ligandmediated receptor activation leads to activation of downstream signalling pathways that in turn lead to caspases-

*Address correspondence to this author at the Institute of Genetics and Molecular Medicine, Edinburgh CRUK Research Centre, Cancer Biology, Crewe Road South, Edinburgh EH4 2XR, UK; Tel: +44 (0)131 777 3555; E-mail:mditzel@ed.ac.uk activation [6]. Therefore, extracellular-based instructions can govern the ultimate fate of a cell within an organ or tissue - a statement that is also applicable to morphogens.

Regardless of the type or source of apoptotic signal, caspases, a group of aspartate-directed proteases, lie at the heart of the cells' core death machinery [8]. Both the intrinsic and extrinsic pathways activate caspases, which in turn protealytically activate pro-apoptotic and disable antiapoptotic proteins [9]. This caspase-orchestrated cleavage of apoptotic regulators ultimately results in cleavage of essential regulators of cellular and genomic integrity [9]. To prevent an inflammatory response, the cell's remains are packaged into membrane bound apoptotic bodies and subsequently engulfed by macrophages and neighbouring cells [10].

\section{Morphogens}

At a molecular level morphogens can be described as molecules that emanate from a localised source to form a concentration gradient. While at a functional level they act as core organisers of cell patterning, cell fate and ultimately overall tissue morphology [11]. These morphogen-coordinated events, incorporating growth, proliferation and cell death permit the exceptional three-dimensional structural complexity of organs.

Of the known morphogens, Bone Morphogenic Proteins (BMPs) [12], Notch [13], Wnts [14] and Hedgehog [15] family members are evolutionary conserved. All four share an ability to (A) act directly on a cell through, in most cases, receptor engagement to elicit (B) qualitatively distinct cellular outcomes in response to different morphogen concentrations/gradients. Therefore a cell's position within a morphogen concentration gradient determines the state of the cell's intracellular signalling pathways and gene expression profiles. Intriguingly, through distinct mechanisms, morphogen-associated signalling pathways can instigate, as well as suppress, apoptosis (see following sections). Unsurprisingly, defects in these potent signalling pathways manifest in numerous diseases and developmental defects [16]. 
The ability of a morphogen to confer distinct cellular fates is effected by the cells' ability to perceive quantitative differences in the slope as well as the absolute concentration of the ligand $[17,18]$. Morphogen receptors, unlike more conventional binary "on/off" receptors, are capable of translating quantitative differences in ligand levels/gradients into distinct cellular outcomes. In most cases, differences in morphogen concentrations affect the activation level/specific activity of key transcriptional effectors. And it is these differences in transcription factor activities that initiate differential patterns of gene expression and determine cellular outcomes. Hence morphogens represent potent and complex intercellular signalling molecules whose message is interpreted in a context-specific manner.

In a developing tissue individual cells encounter combinations of different morphogen gradients. Integration of this information by a cell is further influenced by crosstalk and cross-regulation between different morphogen- and non-morphogen-signalling pathways [19]. Cross-talk between pathways occurs at the level of target genes - for example WNT [20], Notch [21] and Hedgehog [22] pathways promote, while BMP pathways [23] repress $M Y C$ expression. Cross-regulation of one morphogen's expression by another is a frequently used mechanism and the example of Hedgehog-mediated expression of pro-apoptotic BMPs will be discussed later.
Due to the sheer breadth of morphogen research, this review will focus upon the pro and anti-apoptotic signalling functions of the Hedgehog family of morphogens: Drosophila Hedgehog $(\mathrm{HH})$ and vertebrate Sonic-, Desertand Indian-Hedgehog ( $\mathrm{SHH}, \mathrm{DHH}$ and $\mathrm{IHH}$, respectively). Please note that in the text the $\mathrm{HH}$ pathway denotes a generalised Hedgehog-family-member pathway, not just that of the Drosophila HH. Overall, this review aims to focus on HH's ability to influence multiple apoptotic signalling pathways and its relevance to disease and development.

\section{Canonical HH Signalling Pathway}

The canonical HH-pathway governs the majority of Hedgehog's mitogenic and morphogenic effects [16] (Fig. 1) and acts through regulating the activity of Smoothened (SMO) [24] - a seven-transmembrane G-protein coupled receptor-like protein. In the absence of $\mathrm{HH}$, Patched (PTC), Hedgehog's cognate 12-transmembrane receptor protein [25], blocks SMO and as a consequence represses the downstream signalling pathway (Fig. 1). Upon binding of $\mathrm{HH}$ to PTC, SMO is derepressed and activates a signalling cascade of post-translational modifications [15] that promotes activation of a family of Glioma-associated oncogene homolog (GLI) transcription factors [26]. These in turn transcriptionally activate the pathway's target genes that include those involved in cell cycle entry [27], proliferation [22], angiogenesis [28], axonal guidance [29] and epithelial-
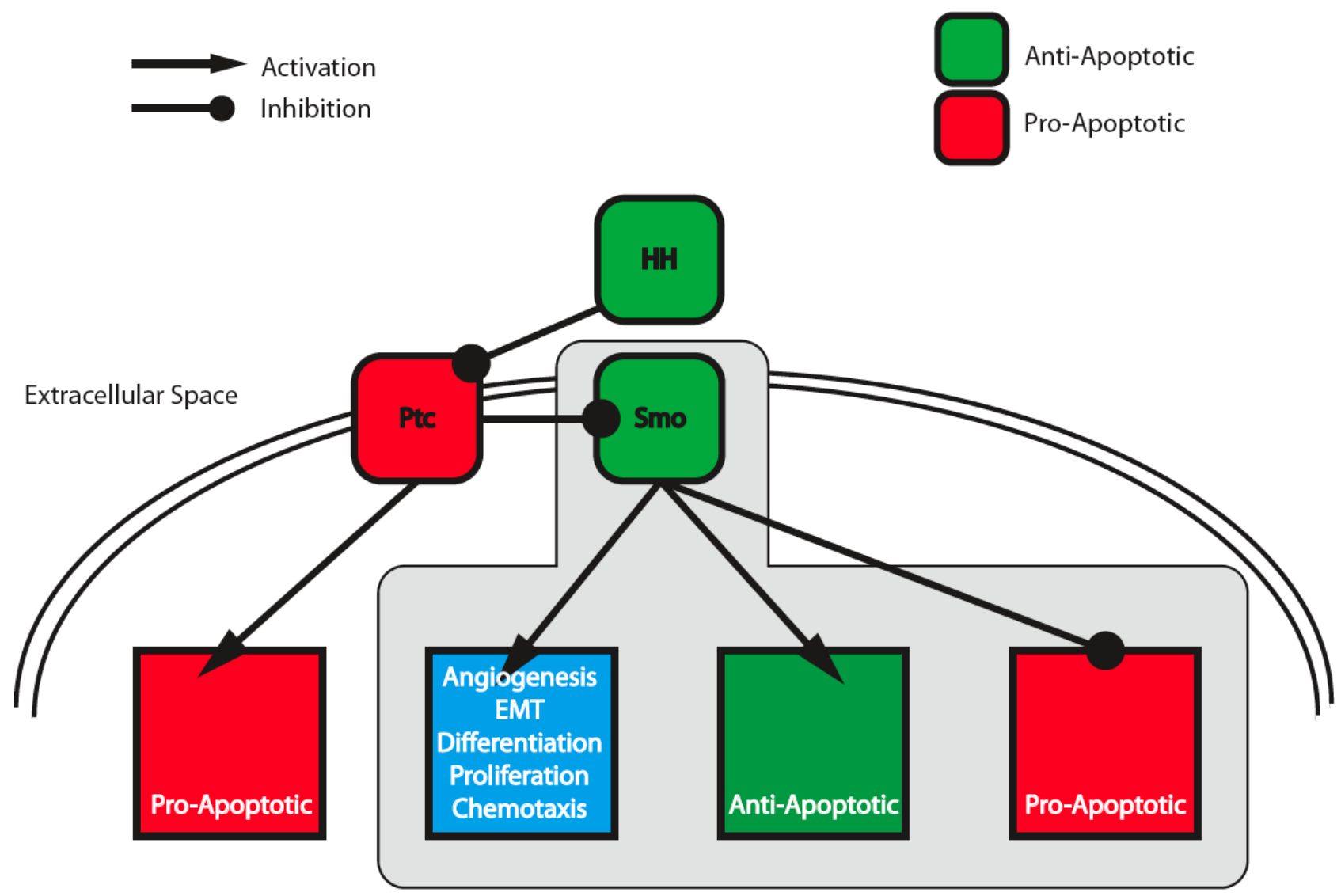

Fig. (1). Basic Overview of the PTC- and SMO-associated Signalling Pathways and their Cellular Outcomes. PTC governs the activity of a pro-apoptotic pathway (red square), while SMO governs the activity of the canonical elements of the HH-pathway, including the indicated non-apoptotic cellular outcomes (blue square) and pro- and anti-apoptotic (green square) signalling pathways. HH - Hedgehog; PTC $=$ Patched; SMO = Smoothened. Anti- and pro-apoptotic proteins (round-edged squares) are labelled green and red respectively. 
mesenchymal transition [30].

Vertebrates encode three family members [31]: GLI-1 (a potent transcriptional activator), -2 (transcriptional activator and repressor functions) and -3 (predominantly a transcriptional repressor). In an unstimulated cell $G L I-1$ is not expressed and GLI-2 and -3 are protealytically processed and converted into transcriptional repressors. GLI-2 and -3 are maintained in their repressor forms through phosphorylation-mediated ubiquitylation and subsequent cleavage [32]. Upon HH stimulation, both GLI-2 and 3 are no longer cleaved and GLI-1 is now expressed. Together the lack of GLI-2 -3-mediated transcriptional repression, conversion of GLI-2 into an activator and expression of GLI1 results in transcriptional activation of target genes.

\section{Role of Canonical Pathway in Apoptosis}

Activation of the canonical Hedgehog pathway can suppress apoptosis through transcriptional upregulation of potent inhibitors of both the extrinsic and intrinsic apoptotic pathways. Hence, aberrant $\mathrm{HH}$ signalling in human tumours provides an effective means of evading apoptosis. For example basal cell carcinomas are subjected to apoptotic signals due to expression of the pro-apoptotic TRAIL (Tumour necrosis factor-Related Apoptosis-Inducing Ligand) ligand and its receptors, TRAIL receptor 1/2 (also called DR4 and DR5, respectively) [33]. However, they also harbour mutations in SMO or PTC that result in ligandindependent activation of the canonical $\mathrm{HH}$ signalling pathway [34]. Resulting in a reduction of cells' ability to either promote pro-, or suppress anti-apoptotic pathways. One repressed target of the pathway is the TRAIL receptor 1 and HH-mediated expression of FLIP (FLICE-Like Inhibitory Protein) [33] blocks TRAIL-mediated activation of Caspase- 8 and hence the apoptotic caspase cascade. Similarly $\mathrm{HH}$-mediated $\mathrm{Bcl} 2$ overexpression [35, 36] also blocks the tumours' increased apoptotic load generated by oncogene activation and increased metabolic stress [37]. As a potent anti-apoptotic protein frequently overexpressed in numerous cancers, $\mathrm{Bcl} 2$ acts to prevent the release of cytochrome c from the mitochondria [38] (and Grant Dewson's review in this issue). This in turn prevents cyctochrome-c-mediated apoptosome formation, Caspase-9 activation and initiation of the apoptotic caspase cascade. Therefore a combination of potent apoptotic inhibitors, induced by the $\mathrm{HH}$ pathway, would render cells impervious to two major routes of apoptotic induction.

In addition to the anti-apoptotic transcriptional targets, the canonical HH signalling pathway may also use posttranslational modifications to regulate the levels and activity of the central apoptotic regulator p53. HH-mediated activation of SMO may promote PI3K-mediated activation of the anti-apoptotic AKT pathway [39] and promote MDM2-mediated p53 degradation [40]. Removal of p53, a key integrator of diverse apoptotic signals, again would cause cells to resist many types of apoptotic insults.

The HH pathway's ability to protect cells from both intrinsic, through Bc12, loss of p53 and activation of cell survival pathways, and extrinsic mechanisms, through FLIP, highlights its role as a central player in apoptotic regulation. Therefore, in combination with its more established role in promoting cell growth and division, aberrant activation of the canonical $\mathrm{HH}$ pathway can provide both the drive towards, and inhibition of the pro-apoptotic brake(s) against, tumourigenesis. Nevertheless, the $\mathrm{HH}$ pathway has additional pro- and anti-apoptotic regulatory roles that will be discussed in the following sections.

\section{Hedgehog's Anti-Apoptotic Role in Development}

A number of elegant developmental studies with mice and chicken have revealed a major anti-apoptotic role for $\mathrm{HH}$ in a range of cells within different tissues. Midline cells (notochord and floorplate) in developing chick [41-43] and mouse [44-46] embryos provide SHH-derived survival and proliferative signals to the surrounding tissue. Surgical procedures that prevent regression of Hensen's node (the avian organiser) prevent the formation of the midline cells, but allow the formation the neural tube [41]. In the absence of midline cells - the source of SHH - all the tissue surrounding the midline-depleted region, including the neural tube, undergo apoptosis. This massive cell death could be rescued by grafting of SHH expressing cells in the midline-depleted animal [41]. Similar observations were also made for midline-derived SHH in promoting the survival of myogenic and chondrogenic cell lineages [43].

In the mouse, ectopic expression of $\mathrm{SHH}$ in the dorsal neural tube inhibits differentiation and increased cell numbers [47]. Mice deficient in Shh exhibit gross defects in patterning and tissue organisation and only survive up to or just after birth [45]. Loss of SHH expression in a Shh null animal led to extensive somite and neural crest cell death $[45,48]$. In contrast, loss of Ptc function leads to overgrowth phenotypes in both homozygous mouse embryos and heterozygous adults [49]. These observations are consistent with a role for PTC in both promoting cell death and suppressing proliferation. Furthermore, injection of $\mathrm{SHH}$ blocking antibodies in the cephalic region of chick embryos led to massive apoptosis in the neural tube and neural crests regions $[50,51]$.

\section{SHH as a Survival Factor in Tumour Cells}

Therapeutic intervention to block the $\mathrm{HH}$ pathway and its ability to suppress apoptosis, differentiation and promote proliferation has proven extremely effective in the treatment of a number of human tumours [52]. Hedgehog's mode of action may be cell autonomous or cell non-autonomous, acting in either an autocrine or paracrine manner, respectively [53]. In an autocrine model tumour cells both produce and respond to $\mathrm{HH}$, while in the paracrine model $\mathrm{HH}$ produced by the tumour signals to the surrounding stroma. These stromal cells can then indirectly benefit the tumour cells by, for example, mediating angiogenesis [54]. A reverse paracrine model may also function where tumour cells drive tumourigenesis by actively signalling to surrounding stromal cells to produce $\mathrm{HH}$. Furthermore, $\mathrm{HH}$ signalling to the stroma may in turn promote production of alternative extracellular signalling molecules such as Insulinlike growth factor (IGF) [55] and directly promote tumour growth and/or survival.

Basal cell carcinoma provided direct evidence for a role for $\mathrm{HH}$ in human cancer. Patients harbour mutations in either $P T C$ or $S M O$ that render pathway activation ligand independent [34]. This HH-independent method of activating 
the pathway seems to be rare in other tumour types, with the majority of tumours being dependent on either autocrine or paracrine modes of actions [56]. Numerous studies have identified $\mathrm{HH}$-signalling as being essential to the survival of tumour cells derived from a wide variety of tissues: small cell lung cancer [57]; oesophageal, stomach, biliary tract and pancreatic cancers $[58,59]$, multiple myeloma $[60,61]$, leukemias [62] and gliomas and other brain tumours [63]. Furthermore, in Helicobacter pylori induced gastric cancer, gastric epithelial cells reactivate expression of $\mathrm{SHH}$ and, through an autocrine loop, confers resistance to apoptosis [64].

\section{Pro-Apoptotic Role of SHH}

While generally considered to be a survival signal, $\mathrm{SHH}$ also seems to play a pro-apoptotic role in some developmental death processes. Cells eliminated at the fusion of the neural folds require $\mathrm{SHH}$-mediated apoptosis, while certain cells in the spinal cord exhibit apoptotic responses to $\mathrm{SHH}$ signalling [65]. Furthermore, in the chick developing limb bud, SHH expressing cells in the zone of polarising activity undergo SHH-mediated homeostatic apoptosis. This action is key to maintain the correct spatial positioning and prevent the overexpansion of the zone of polarising activity [66]. Programmed cell death occurring in the developing vertebrate limb is one of the clearest examples of apoptosis as a morphogenetic process [67]. Similarly, the morphogenic role of $\mathrm{HH}$ is extremely well characterised [68]. Its exclusive expression in a distinct "polarising region" establishes a morphogen gradient essential for the correct growth and patterning of the vertebrate limb. Within the developing limb four clear areas undergo massive apoptosis that control digit formation and separation - namely the opaque patch, anterior-, and the posterior-necrotic zones and interdigital areas [69].

In the posterior-necrotic zone, exogenous SHH promotes apoptosis but suppresses death in three other regions [66]. Such radical differences in cellular fate most likely reflect differences in an individual cell's position within a $\mathrm{HH}$ concentration gradient and/or the integrated actions of other extracellular signalling pathways. Although in the minority, similar pro-apoptotic effects of exogenous SHH occur in the avian spinal cord that result in a loss of neuronal precursor cells and floor plate cells [65].

Recent work with conditional Ptc knockout mice revealed the importance of paracrine $\mathrm{HH}$ signalling in the control of haematopoiesis [70]. Deleting Ptc in haematopoietic cells did not lead to activation of the $\mathrm{HH}$ pathway or generate a phenotype. Conversely, loss of Ptc in the surrounding non-haematopoietic cells led to autonomous $\mathrm{HH}$ pathway activation and correlated with apoptosis of haematopoietic early T- and B-cell precursors.

\section{Patched, the Hedgehog Receptor as a Pro-Apoptotic Dependence Receptor}

With the exceptions of the few examples given above, the majority of evidence points to a role for the canonical pathway, via SMO, in suppressing apoptosis. However, more recent work however has highlighted a role for PTC in pro- apoptotic signalling, independent of the SMO-associated canonical pathway $[41,71]$. These findings demonstrate a bifurcation of the Hedgehog signalling pathway downstream of the PTC receptor into canonical and non-canonical branches (see Fig. 1). Furthermore they suggest that HHmediated regulation of apoptosis simultaneously relies on regulation of separate intracellular signalling pathways governing (A) PTC-mediated pro-apoptotic signalling and (B) SMO-mediated anti-apoptotic signalling.

PTC's pro-apoptotic function in the absence of $\mathrm{HH}$ places PTC as a member of a family of "dependence receptors" [72]. The family includes: DCC (deleted in colorectal cancer), TrkC (tyrosine kinase receptor C), ALK (anaplastic lymphoma kinase), RET (rearranged during transfection), $\alpha v \beta_{3}$ integrin, p75NTR (p75 neurotrophin receptor), neogenin, and androgen receptor. These proteins along with PTC are grouped by their shared properties/ abilities to: (1) induce cell death in the absence of their cognate ligand; (2) induce caspase-dependent cell death; (3) undergo a pro-apoptotic modification/alteration of a cytoplasmic domain; (4) play a role in both developmental processes, most commonly neurogenesis, and cancers; and (5) potentially contain a dependence receptor associated transmembrane motif (DART) [73]. PTC matches all five of the above criteria and may explain some of the apoptotic response of cells deprived of $\mathrm{HH}$.

PTC overexpression, in the absence of SHH, activates caspases, promotes DNA fragmentation and is suppressed with the pan-caspase inhibitor z-VAD [41]. PTC deletion and mutation analyses identified a region in the seventh intracellular loop of PTC essential for its apoptotic signalling. Furthermore this region promotes the formation of a pro-apoptotic multiprotein complex named the "dependosome" [71]. Within this region of murine PTC resides a caspase cleavage site $\left(\operatorname{PETD}^{1392} \Downarrow_{\mathrm{H}}\right)$ [41] and cleavage at this site by the effector Caspase- 3 and -7 , or initiator Caspase-8 was required for PTC-mediated apoptosis. Expression of the amino-terminal cleaved portion (PTC $^{1-1392}$ ) was sufficient to induce apoptosis and was refractory to SHH-mediated protection. Moreover a noncaspase-cleavable mutant, PTC PETN ${ }^{1392} \mathrm{H}$, was unable to promote cell death.

More recent molecular analysis of PTC receptor complexes identified a number of apoptotic and caspaseassociated proteins [71] (Fig. 2). Within this complex reside the initiator Caspase-9, the LIM-domain-containing DRAL (Down-regulated in Rhadomyosarcoma) and the CARDcontaining proteins TUCAN (tumour-up-regulated CARDcontaining antagonist of Caspase nine) and NALP1 (NLR family, pyrin domain containing 1). DRAL bridges PTC to TUCAN, which in turn recruits Caspase-9. The presence of this initiator caspases within the complex provides an obvious link to the intrinsic apoptotic pathway. In the absence of $\mathrm{SHH}$, the multiprotein complex including Caspase-9 assembles and leads to activation of the downstream caspase-cascade. While in the presence of $\mathrm{SHH}$ caspases are not activated, the multiprotein complex dissembles and cells do not die. 

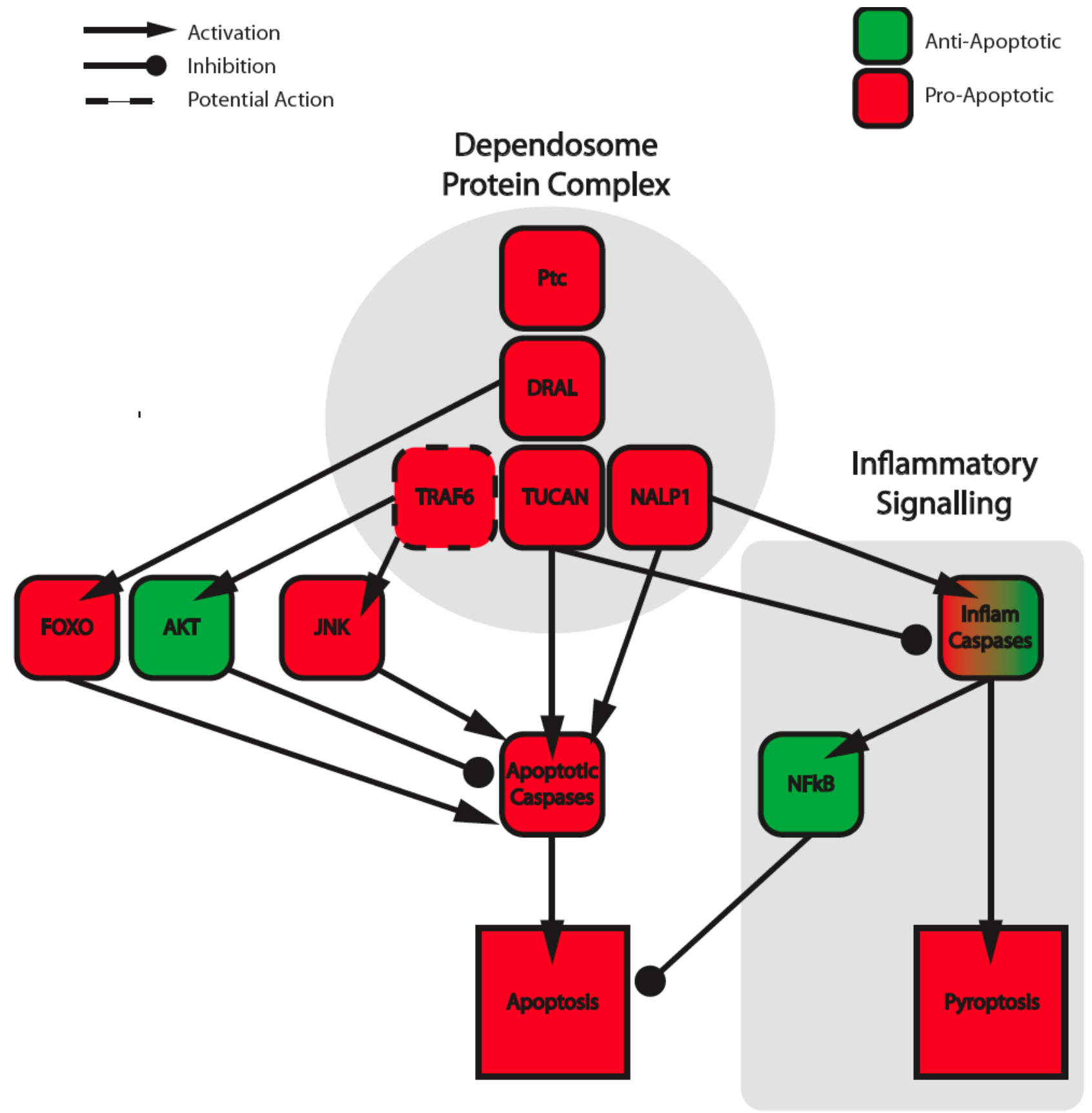

Fig. (2). The Dependosome Multi-protein Complex and its Downstream Effectors. In the absence of HH, PTC binds DRAL, which recruits TUCAN, NALP1 and potentially TRAF6. Both TUCAN and NALP1 can regulate inflammatory mediators and pro-apoptotic caspase activation. Inflammatory caspases (Inflam Caspases) activate the NFKB pathway and in certain circumstances a specific form of apoptosis called pyroptosis. In addition to acting as a scaffold, DRAL can also enhance FOXO transcriptional activity and activate caspases. TRAF6, if present in the complex, can influence pro- and anti-apoptotic signalling through JNK and AKT, respectively. PTC $=$ Patched; DRAL $=$ Down-regulated in Rhadomyosarcoma; TRAF6 = TNF Receptor Associated Family 6; TUCAN = Tumour-up-regulated CARD-containing Antagonist of Caspase Nine; NALP1 = NLR family, pyrin domain containing 1; FOXO = Forkhead Box Class O); AKT = AK-strain Transforming or Protein Kinase B; JNK = Jun N-terminal Kinase; NfאB = Nuclear Factor Kappa B. Anti- and pro-apoptotic proteins (roundedged squares) are labelled green and red respectively. Please note, in this scenario TRAF6 is considered pro-apoptotic and NfkB is considered anti-apoptotic.

While Caspase-9 provides the most obvious link to apoptosis [5], the other multi-protein complex components also have links to apoptotic regulation (see following section for more details). Intriguingly, DRAL, TUCAN and NALP1 have known roles in the regulation the NFKB pathway [74]. This pathway has a complex association with apoptosis as it both promotes and suppresses cell death [75]. Nevertheless this link between PTC and the NfkB pathway provides a potential molecular mechanism for PTC-mediated apoptosis. As a number of the proteins identified in the 'dependosome' have been linked to alternative apoptotic and caspaseactivational pathways, it is possible that the dependosome 
may act as a central hub for activating multiple, independent routes for apoptotic initiation.

\subsection{Apoptosis-Associated Roles of PTC Dependosome Subunits}

\subsubsection{DRAL/FHL2}

DRAL/FHL2 is a four and a half LIM domain containing protein that primarily acts as a transcriptional co-activator or repressor for a number of target genes [76, 77]. Caspasemediated cleavage of PTC is essential for its pro-apoptotic activity and its interaction with the LIM2-containing region of DRAL [71]. Upon overexpression, DRAL promotes apoptosis in a number of cell lines and fits with its role as a p53 target gene [78]. In addition to its above-mentioned role in recruiting Caspase-9, mechanistically, FHL2 may be affecting apoptosis through recruitment of TRAF6 and its associated apoptosisregulatory complexes [79]. Both pro-apoptotic TGF $\beta$ - and RANK-receptors recruit TRAF6, which in turn activates TAK1 and leads to increased JNK activity $[80,81]$. As with the $\mathrm{HH}$ pathway, under certain circumstances the RANK- and TGF $\beta$ receptors can provide anti-apoptotic signals. Both TGF $\beta$ [82] and RANKL [83] use TRAF6 and SRC to mediate anti-apoptotic signalling through the PI3K/AKT survival pathway [84].

An alternative link to apoptosis includes FHL2's ability to bind the pro-apoptotic Forkhead transcription factor FOXO1 and blocks its transcriptional activity [85]. While FHL2 also acts on other transcriptional regulators including SMADs 2, 3 and 4 [86] and $\beta$-catenin [77] to regulate key cell cycle regulators. FHL2 could also act to suppress survival signalling through binding integrins and blocking integrin-mediated ERK signalling [87].

\subsubsection{TUCAN/CARD8}

TUCAN is a CARD-containing protein that is expressed as $48 \mathrm{kDa}$ and $54 \mathrm{kDa}$ isoforms. Through a homophilic CARD-CARD interaction, the smaller form binds Caspase-9 and blocks a variety of intrinsic-pathway activating insults $[88,89]$. In contrast the $54 \mathrm{kDa}$, which contains a unique amino-terminus absent in $48 \mathrm{kDa}$ form, binds FADD and blocks FasL- and extrinsic Caspase-8-mediated apoptosis [89]. Nevertheless, contradictory findings suggest that TUCAN can also assume pro-apoptotic roles. Upon overexpression TUCAN blocked Caspase-1 processing, the production of IL1- $\beta$, suppressed the NFKB pathway and ultimately sensitised cells to PMA-induced apoptosis [90].

\section{$\underline{\text { 8.1.3. NALP1 }}$}

NALP1 is a member of the NOD-like receptor family involved the recognition of viruses and microbes and subsequent activation of the innate immune system [91]. At the molecular level NALPs promote the formation of large multi-protein signalling complexes called inflammasomes that activate inflammatory Caspases- $1,-4$ and -5 [92]. While inflammatory caspases are associated with apoptosis of infected macrophage apoptosis - called pyroptosis [93] these caspases are predominantly involved in processing inflammatory cytokines such as Interleukin- $1 \beta$ and -33 and promoting the inflammatory response [94]. Upon processing, interleukins - as extracellular signalling molecules - bind their cognate receptors and, in an autocrine or paracrine manner, activate the NFKB pathway [95].
In addition to NALP1's role in the inflammasome, it also binds to the anti-apoptotic Bcl2 and Bcl-XL proteins [96]. These interactions repress NALP1-mediated Caspase-1 activation, however the affect on Bcl2 and Bcl-XL's antiapoptotic activity remains unknown. Nevertheless, a clear role for NALP1 in promoting apoptosis comes from its ability to interact with the pro-apoptotic apoptosome component Apaf-1 and promote cell death [97].

\section{Hedgehog-Mediated Apoptosis via a BMP-Autocrine Loop}

In addition to the role of PTC in dependosome-signalling, a second canonical-pathway-associated apoptotic pathway can also promote Caspase-9 activation. In the absence of $\mathrm{HH}$, the cleaved GLI- ${ }^{\mathrm{R}}$ repressor form mediates some of the ectopic apoptosis seen in the neural tube and developing limbs $[46,98,99]$. Aberrant neural tube cell and developing limb apoptosis seen in Shh null mice is rescued in a $S h h^{-1-}$ ;Gli- - $^{--}$null animal [46]. Therefore, with respect to cell survival, the canonical SHH pathway primarily acts to prevent the processing of full-length GLI-3 into its cleaved GLI- $3^{\mathrm{R}}$ form. A number of observations correlate increased levels of apoptosis with increased expression of GLI- $3^{\mathrm{R}}$ and the morphogen BMP4 [98, 99]. Apoptosis associated with BMP signalling occurs in a number of tissues throughout development and includes the developing limb buds [67]. One mechanism acts to activate Caspase-9 through stabilisation of $\mathrm{p} 53$ and subsequent expression of the proapoptotic BH3-only proteins PUMA [100] or BIM [101].

GLI-mediated transcriptional activation of BMP4 and BMP7 promoters [102] provides a direct molecular link between the HH and BMP morphogen pathways. Therefore, when depleted of ligand, the HH pathway is unable to prevent the formation of GLI- $3^{R}$, which in turn leads to production of BMPs. Additionally, in the presence of ligand, HH signalling upregulates expression of the BMP antagonist Gremlin [98]. During limb morphogenesis, this BMP-binding protein's expression correlates with a lack of apoptosis and, in its absence, with cell death. In the developing duck embryo, non-apoptotic interdigital tissue expresses Gremlin, while the apoptotic interdigital tissue of a chick lacks it [103]. Therefore in the absence of SHH, a combination of events promotes BMP-mediated apoptosis: (1) by increased production of BMP4 ligand and (2) decreasing levels of its inhibitory binding-protein Gremlin (Fig. 3).

The above example demonstrates that when active one morphogen pathway (HH) directly suppresses ligand production of another (BMPs). In turn, when active the BMP pathway represses the expression a third, anti-apoptotic associated morphogen, Fibroblast Growth Factor 8 (FGF8). Therefore, through regulating BMP expression, the $\mathrm{HH}$ pathway indirectly promotes FGF8 expression [104]. In the $S h h^{-/-}$null mouse, apoptotic cells in or around apoptotic tissues not only show elevated levels of BMP $4 / 7$, but also lack FGF8 expression [105]. In the interdigital regions of the developing limbs, FGF8 acts as a cell survival factor [106]. Inactivation of FGF8 results in ectopic cell death in the development of the early limb bud [107, 108], kidney [109, $110]$ and brain $[111,112]$. Activation of both RAS-MAPK and PI3K-AKT cell survival pathways are associated with the FGF receptors engagement [113] and therefore provides a powerful means to control apoptosis. 

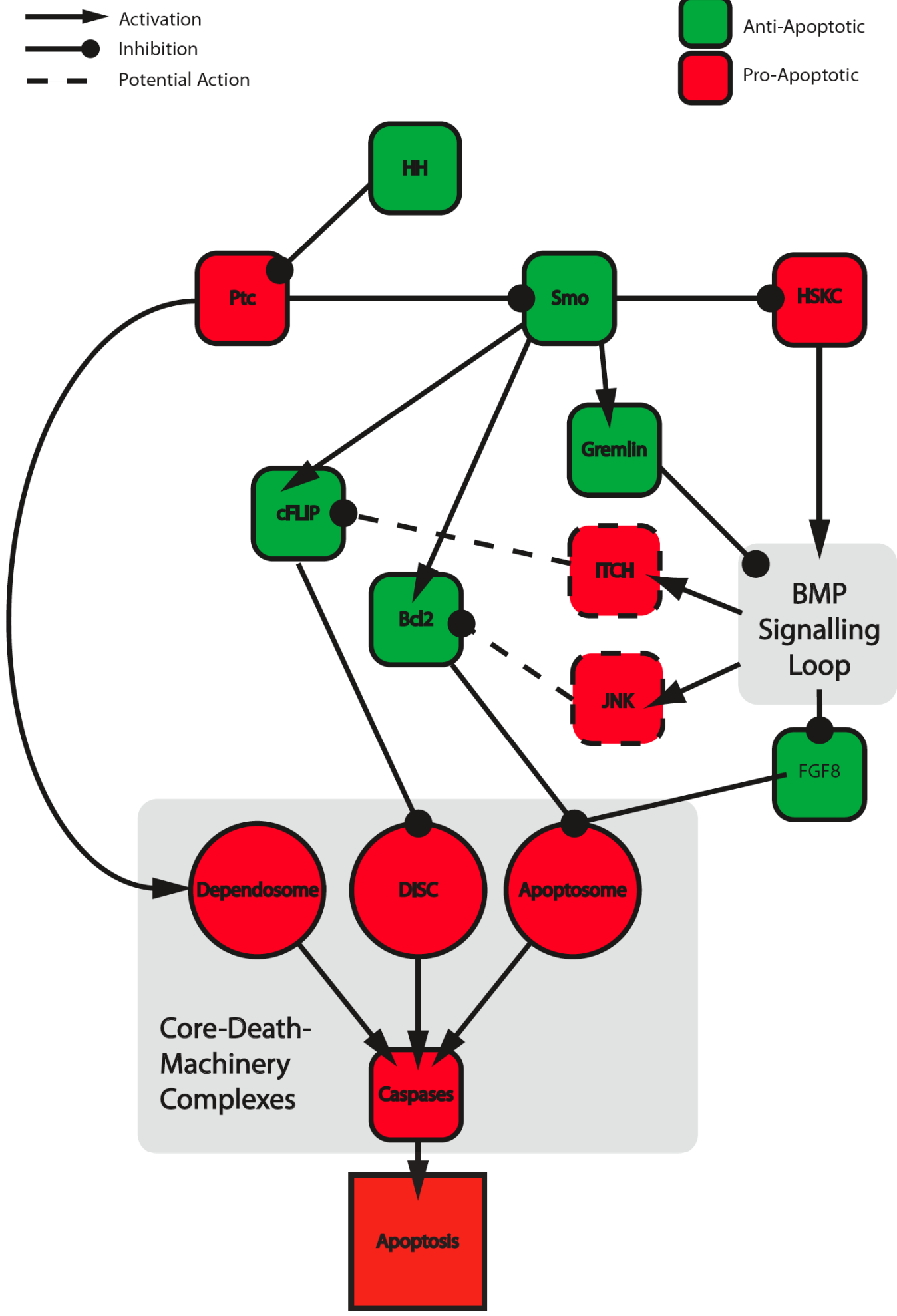

Fig. (3). Overview of Apoptotic Regulation by the HH-pathway. SMO activates the Hedgehog signalling kinase complex (HSKC) [119] that in turn promotes anti-apoptotic actions through GLI-1 and -2 and suppresses pro-apoptotic actions through GLI- $3^{\mathrm{R}}$. The GLI-1 and-2 pathway induces the expression of inhibitors of the intrinsic $(\mathrm{Bcl} 2)$, extrinsic (FLIP) and GLI- $3^{\mathrm{R}}$-regulated BMP4/7-autocrine (Gremlin) apoptotic pathways. These distinct apoptotic pathways regulate the indicated Core-death-machinery complexes (red circles $=$ Dependosome, Death Inducing Signalling Complex (DISC) and Apoptosome). All three complexes activate initiators caspases, which in turn activate effector caspases and mediate apoptosis. GLI-3 ${ }^{\mathrm{R}}$ governs a pro-apoptotic autocrine-signalling loop, by transcriptionally upregulating Bone Morphogenic Proteins 4/7 (BMP4/7). These then bind the Bone Morphogenic Protein Receptor 1 (BMPR1), repressing FGF8 expression and activating JNK. Phosphorylation of JNK substrates leads to inhibition of the anti-apoptotic molecules Bcl2 (B-cell lymphoma/leukaemia 2 gene) and FLIP (Flice/Caspase-8-Inhibitory Protein) - see text for details. Anti- and pro-apoptotic proteins (round-edged squares) are labelled green and red respectively. Please see Figure 2 for a more detailed schematic of the Dependosome. 
At the molecular level, BMP-signalling through ligand engagement of the BMP receptor (BmpR1A) mediates loss of FGF8 expression [105]. While this provides a molecular link between the two morphogen-signalling pathways, it is unlikely to be the sole apoptotic consequence of elevated BMP signalling. As with the SHH receptor PTC, ligand engagement of BMP-family Transforming Growth Factor $\beta$ receptors (TGF- $\beta$ R) affects two distinct downstream signalling pathways. One relies on a transcriptional output mediated by a group of transcriptional co-regulators called SMADs [114]. Upon binding of the TGF $\beta$ ligand, TGF $\beta$ RIand TGF $\beta$ RII-receptors activate SMADs and sensitise cells to apoptosis by transcriptionally downregulating antiapoptotic $B C L-2$ [115] and upregulating pro-apoptotic $B I M$ [116].

In addition to a SMAD-mediated transcriptional response, post-translational modifications can also drive TGF $\beta$ mediated apoptotic responses. Upon TGF $\beta$-receptor ligation, TGßR-mediated phosphorylation activates the E3 ubiquitinprotein ligase TRAF6 and promotes its non-degradative K63-linked autoubiquitylation [80]. TGF- $\beta$-activated kinase 1 (TAK1) is then activated upon binding to ubiquitylated TRAF6. Once active TAK1 initiates a kinase cascade to activate the stress-activated kinases JNK and p38 [81] (see Fig. 3). These kinases are capable of promoting both developmental and stress-induced apoptosis and are activated in response to a range of cellular insults [117]. As discussed earlier PTC may also recruit TRAF6 via FHL2 to activate $\mathrm{JNK} / \mathrm{p} 38$ and promote apoptosis. Regardless of the route of $\mathrm{JNK} / \mathrm{p} 38$ activation, these kinases effect apoptosis $[117,118]$ via (1) nuclear translocation of c-JUN and subsequent expression of pro-apoptotic genes; (2) direct phosphorylation and activation of $\mathrm{p} 53$; (3) degradation of FLIP, via phosphorylation and activation of the ubiquitinprotein ligase ITCH; and (4) activation and suppression of pro-apoptotic $\mathrm{BH} 3$-only protein and anti-apoptotic $\mathrm{Bcl} 2$ family members, respectively.

\section{CLOSING REMARKS}

In summary, components of the HH-pathway can both directly promote and suppress apoptosis (Fig. 3). Unfortunately, a clear link between the presence, or absence, of ligand and promotion or suppression of apoptosis cannot currently be made. In the presence of ligand the HH-pathway can actively suppress apoptosis through both blocking proand activating anti-apoptotic proteins. However, under certain developmental circumstances, the presence of $\mathrm{HH}$ and activation of the pathway promotes apoptosis (see Section 8). Nevertheless, in the absence of ligand, apoptosis does seem to predominate, with two separate signalling pathways converging on caspases to promote cell death. The first stems from PTC-mediated formation of the "dependosome", which should prompt the apoptotic field to rethink the exclusive association between extracellular (extrinsic) pathways and Caspase-8 activation. And the second stems from SMO-associated processing of GLI-3 into its GLI- $3^{\mathrm{R}}$ form. These two pathways significantly differ, with the former directly activating Caspase- 9 and the latter acting indirectly through autocrine action of second messengers (BMPs).
With the majority of our knowledge being derived from in vivo animal studies, such results reflect the complex environment an individual cell experiences in a particular tissue and timeframe. Within these settings individual cells perceive temporally and spatially restricted instructions from a wide array of extracellular signalling molecules (see Review by Paul Ekert in this issue) - that include morphogens. In the case of morphogens, cellular responses are not only dependent on the presence or absence of the ligand, but also slope of the ligand gradient. In combination with the other extracellular signalling molecules, cells must translate and integrate this information through intracellular pathways. These in turn initiate molecular programmes that effect cellular outcomes. Due to a significant degree of cross-talk and cross-regulation between different pathways [19] the molecular and cellular outcomes of morphogenstimulation can be altered. Such contextual determinants may help explain the apparent pro- and anti-apoptotic duality of HH-signalling. Only more detailed in vivo studies will allow us to identify the molecular circuits that ultimately determine morphogen-associated outputs.

\section{ACKNOWLEDGEMENTS}

I would like to thank Dr. Val Brunton for her input in improving the manuscript. Mark Ditzel is funded by the University of Edinburgh as a Senior Research Fellowship and as a BBSRC New Investigator Award.

\section{REFERENCES}

[1] Fan Y, Bergmann A. Distinct mechanisms of apoptosis-induced compensatory proliferation in proliferating and differentiating tissues in the Drosophila eye. Dev Cell 2008; 14(3): 399-410.

[2] Adachi-Yamada T, O'Connor MB. Mechanisms for removal of developmentally abnormal cells: cell competition and morphogenetic apoptosis. J Bio chem 2004; 136(1): 13-7.

[3] Cotter TG. Apoptosis and cancer: the genesis of a research field. Nat Rev Cancer 2009; 9(7): 501-7.

[4] Clarke P, Tyler KL. Apoptosis in animal models of virus-induced disease. Nat Rev Microbiol 2009; 7(2): 144-55.

[5] Riedl SJ, Salvesen GS. The apoptosome: signalling platform of cell death. Nat Rev Mol Cell Biol 2007; 8(5): 405-13.

[6] Peter ME, Krammer PH. The CD95(APO-1/Fas) DISC and beyond. Cell Death Differ 2003; 10(1): 26-35.

[7] Vince JE, Wong WW, Khan N, et al. IAP antagonists target cIAP1 to induce TNFalpha-dependent apoptosis. Cell 2007; 131(4): 68293.

[8] Pop C, Salvesen GS. Human caspases: activation, specificity, and regulation. J Biol Chem 2009; 284(33): 21777-81.

[9] Fischer U, Janicke RU, Schulze-Osthoff K. Many cuts to ruin: a comprehensive update of caspase substrates. Cell Death Differ 2003; 10(1): 76-100.

[10] Paidassi H, Tacnet-Delorme P, Arlaud GJ, Frachet P. How phagocytes track down and respond to apoptotic cells. Crit Rev Immunol 2009; 29(2): 111-30.

[11] Fuccillo M, Joyner AL, Fishell G. Morphogen to mitogen: the multiple roles of hedgehog signalling in vertebrate neural development. Nat Rev Neurosci 2006; 7(10): 772-83.

[12] Xiao YT, Xiang LX, Shao JZ. Bone morphogenetic protein. Biochem Biophys Res Commun 2007; 362(3): 550-3.

[13] Bray SJ. Notch signalling: a simple pathway becomes complex. Nat Rev Mol Cell Biol 2006; 7(9): 678-89.

[14] MacDonald BT, Tamai K, He X. Wnt/beta-catenin signalling: components, mechanisms, and diseases. Dev Cell 2009; 17(1): 926.

[15] Jiang J, Hui CC. Hedgehog signalling in development and cancer. Dev Cell 2008; 15(6): 801-12.

[16] Varjosalo M, Taipale J. Hedgehog: functions and mechanisms Genes Dev 2008; 22(18): 2454-72.

[17] Ashe HL, Briscoe J. The interpretation of morphogen gradients. Development 2006; 133(3): 385-94. 
[18] Lander AD. Morpheus unbound: reimagining the morphogen gradient. Cell 2007; 128(2): 245-56.

[19] Katoh M. Networking of WNT, FGF, Notch, BMP, and Hedgehog signalling pathways during carcinogenesis. Stem Cell Rev 2007; 3(1): 30-8.

[20] He TC, Sparks AB, Rago C, et al. Identification of c-MYC as a target of the APC pathway. Science 1998; 281(5382): 1509-12.

[21] Weng AP, Millholland JM, Yashiro-Ohtani Y, et al. c-Myc is an important direct target of Notch1 in T-cell acute lymphoblastic leukemia/lymphoma. Genes Dev 2006; 20(15): 2096-109.

[22] Kenney AM, Cole MD, Rowitch DH. Nmyc upregulation by sonic hedgehog signalling promotes proliferation in developing cerebellar granule neuron precursors. Development 2003; 130(1): 15-28.

[23] Sasaki T, Suzuki H, Yagi K, et al. Lymphoid enhancer factor 1 makes cells resistant to transforming growth factor beta-induced repression of c-myc. Cancer Res 2003; 63(4): 801-6.

[24] Alcedo J, Ayzenzon M, Von Ohlen T, Noll M, Hooper JE. The Drosophila smoothened gene encodes a seven-pass membrane protein, a putative receptor for the hedgehog signal. Cell 1996; 86(2): 221-32.

[25] Chen Y, Struhl G. Dual roles for patched in sequestering and transducing Hedgehog. Cell 1996; 87(3): 553-63.

[26] Ruiz i Altaba A. Combinatorial Gli gene function in floor plate and neuronal inductions by Sonic hedgehog. Development 1998; 125(12): 2203-12

[27] Duman-Scheel M, Weng L, Xin S, Du W. Hedgehog regulates cell growth and proliferation by inducing Cyclin D and Cyclin E. Nature 2002; 417(6886): 299-304.

[28] Byrd N, Becker S, Maye P, et al. Hedgehog is required for murine yolk sac angiogenesis. Development 2002; 129(2): 361-72.

[29] Charron F, Stein E, Jeong J, McMahon AP, Tessier-Lavigne M. The morphogen sonic hedgehog is an axonal chemoattractant that collaborates with netrin-1 in midline axon guidance. Cell 2003; 113(1): 11-23.

[30] Li X, Deng W, Nail CD, et al. Snail induction is an early response to Gli1 that determines the efficiency of epithelial transformation. Oncogene 2006; 25(4): 609-21.

[31] Ruiz i Altaba A, Mas C, Stecca B. The Gli code: an information nexus regulating cell fate, stemness and cancer. Trends Cell Biol 2007; 17(9): 438-47.

[32] Jiang J. Regulation of $\mathrm{Hh} / \mathrm{Gli}$ signalling by dual ubiquitin pathways. Cell Cycle 2006; 5(21): 2457-63.

[33] Kump E, Ji J, Wernli M, Hausermann P, Erb P. Gli2 upregulates cFlip and renders basal cell carcinoma cells resistant to death ligand-mediated apoptosis. Oncogene 2008; 27(27): 3856-64.

[34] Epstein EH. Basal cell carcinomas: attack of the hedgehog. Nat Rev Cancer 2008; 8(10): 743-54.

[35] Regl G, Kasper M, Schnidar H, et al. Activation of the BCL2 promoter in response to Hedgehog/GLI signal transduction is predominantly mediated by GLI2. Cancer Res 2004; 64(21): 772431.

[36] Bigelow RL, Chari NS, Unden AB, et al. Transcriptional regulation of bcl-2 mediated by the sonic hedgehog signalling pathway through gli-1. J Biol Chem 2004; 279(2): 1197-205.

[37] Lowe SW, Cepero E, Evan G. Intrinsic tumour suppression. Nature 2004; 432(7015): 307-15.

[38] Youle RJ, Strasser A. The BCL-2 protein family: opposing activities that mediate cell death. Nat Rev Mol Cell Biol 2008; 9(1): 47-59.

[39] Riobo NA, Lu K, Ai X, Haines GM, Emerson CP Jr. Phosphoinositide 3-kinase and Akt are essential for Sonic Hedgehog signalling. Proc Natl Acad Sci USA 2006; 103(12): 4505-10.

[40] Abe Y, Oda-Sato E, Tobiume K, et al. Hedgehog signalling overrides p53-mediated tumor suppression by activating Mdm2. Proc Natl Acad Sci USA 2008; 105(12): 4838-43.

[41] Thibert C, Teillet MA, Lapointe F, Mazelin L, Le Douarin NM, Mehlen P. Inhibition of neuroepithelial patched-induced apoptosis by sonic hedgehog. Science 2003; 301(5634): 843-6.

[42] Charrier JB, Lapointe F, Le Douarin NM, Teillet MA. Antiapoptotic role of Sonic hedgehog protein at the early stages of nervous system organogenesis. Development 2001; 128(20): 401120

[43] Teillet M, Watanabe Y, Jeffs P, Duprez D, Lapointe F, Le Douarin NM. Sonic hedgehog is required for survival of both myogenic and chondrogenic somitic lineages. Development 1998; 125(11): 201930 .

[44] Ulloa F, Itasaki N, Briscoe J. Inhibitory Gli3 activity negatively regulates Wnt/beta-catenin signalling. Curr Biol 2007; 17(6): 54550 .

[45] Chiang C, Litingtung Y, Lee E, et al. Cyclopia and defective axial patterning in mice lacking Sonic hedgehog gene function. Nature 1996; 383(6599): 407-13.

[46] Litingtung Y, Chiang C. Specification of ventral neuron types is mediated by an antagonistic interaction between Shh and Gli3. Nat Neurosci 2000; 3(10): 979-85.

[47] Rowitch DH, B SJ, Lee SM, Flax JD, Snyder EY, McMahon AP. Sonic hedgehog regulates proliferation and inhibits differentiation of CNS precursor cells. J Neurosci 1999; 19(20): 8954-65.

[48] Borycki AG, Mendham L, Emerson CP Jr. Control of somite patterning by Sonic hedgehog and its downstream signal response genes. Development 1998; 125(4): 777-90.

[49] Goodrich LV, Milenkovic L, Higgins KM, Scott MP. Altered neural cell fates and medulloblastoma in mouse patched mutants. Science 1997; 277(5329): 1109-13.

[50] Ahlgren SC, Bronner-Fraser M. Inhibition of sonic hedgehog signalling in vivo results in craniofacial neural crest cell death. Curr Biol 1999; 9(22): 1304-14.

[51] Bronner-Fraser M, Fraser SE. Differentiation of the vertebrate neural tube. Curr Opin Cell Biol 1997; 9(6): 885-91.

[52] Rubin LL, de Sauvage FJ. Targeting the Hedgehog pathway in cancer. Nat Rev Drug Discov 2006; 5(12): 1026-33.

[53] Scales SJ, de Sauvage FJ. Mechanisms of Hedgehog pathway activation in cancer and implications for therapy. Trends Pharmacol Sci 2009; 30(6): 303-12.

[54] Pola R, Ling LE, Silver M, et al. The morphogen Sonic hedgehog is an indirect angiogenic agent upregulating two families of angiogenic growth factors. Nat Med 2001; 7(6): 706-11.

[55] Yauch RL, Gould SE, Scales SJ, et al. A paracrine requirement for hedgehog signalling in cancer. Nature 2008; 455(7211): 406-10.

[56] Theunissen JW, de Sauvage FJ. Paracrine Hedgehog signalling in cancer. Cancer Res 2009; 69(15): 6007-10.

[57] Watkins DN, Berman DM, Burkholder SG, Wang B, Beachy PA, Baylin SB. Hedgehog signalling within airway epithelial progenitors and in small-cell lung cancer. Nature 2003; 422(6929): 313-7.

[58] Berman DM, Karhadkar SS, Maitra A, et al. Widespread requirement for Hedgehog ligand stimulation in growth of digestive tract tumours. Nature 2003; 425(6960): 846-51.

[59] Thayer SP, di Magliano MP, Heiser PW, et al. Hedgehog is an early and late mediator of pancreatic cancer tumorigenesis. Nature 2003; 425(6960): 851-6.

[60] Peacock CD, Wang Q, Gesell GS, et al. Hedgehog signalling maintains a tumor stem cell compartment in multiple myeloma. Proc Natl Acad Sci USA 2007; 104(10): 4048-53.

[61] Zhao $\mathrm{C}$, Chen $\mathrm{A}$, Jamieson $\mathrm{CH}$, et al. Hedgehog signalling is essential for maintenance of cancer stem cells in myeloid leukaemia. Nature 2009; 458(7239): 776-9.

[62] Dierks C, Grbic J, Zirlik K, et al. Essential role of stromally induced hedgehog signalling in B-cell malignancies. Nat Med 2007; 13(8): 944-51.

[63] Clement V, Sanchez P, de Tribolet N, Radovanovic I, Ruiz i Altaba A. HEDGEHOG-GLI1 signalling regulates human glioma growth, cancer stem cell self-renewal, and tumorigenicity. Curr Biol 2007; 17(2): 165-72.

[64] Lee KM, Lee JS, Jung HS, Park DK, Park HS, Hahm KB. Late reactivation of sonic hedgehog by Helicobacter pylori results in population of gastric epithelial cells that are resistant to apoptosis: Implication for gastric carcinogenesis. Cancer Lett 2010; 287(1): 44-53.

[65] Oppenheim RW, Homma S, Marti E, et al. Modulation of early but not later stages of programmed cell death in embryonic avian spinal cord by sonic hedgehog. Mol Cell Neurosci. 1999; 13(5): 348-61.

[66] Sanz-Ezquerro JJ, Tickle C. Autoregulation of Shh expression and Shh induction of cell death suggest a mechanism for modulating polarising activity during chick limb development. Development 2000; 127(22): 4811-23.

[67] Zuzarte-Luis V, Hurle JM. Programmed cell death in the embryonic vertebrate limb. Semin Cell Dev Biol 2005; 16(2): 2619. 
[68] Panman L, Zeller R. Patterning the limb before and after SHH signalling. J Anat 2003; 202(1): 3-12.

[69] Hinchliffe JR. Cell death in vertebrate limb morphogenesis. Progress in Anatomy Vol 2 (ed R J Harrison and V Navaratman). 1982; Cambridge Universisty Press: 1-19.

[70] Siggins SL, Nguyen NY, McCormack MP, et al. The Hedgehog receptor Patched1 regulates myeloid and lymphoid progenitors by distinct cell-extrinsic mechanisms. Blood 2009; 114(5): 995-1004.

[71] Mille F, Thibert C, Fombonne J, et al. The Patched dependence receptor triggers apoptosis through a DRAL-caspase-9 complex. Nat Cell Biol 2009; 11(6): 739-46.

[72] Bredesen DE, Mehlen P, Rabizadeh S. Receptors that mediate cellular dependence. Cell Death Differ 2005; 12(8): 1031-43

[73] del Rio G, Kane DJ, Ball KD, Bredesen DE. A novel motif identified in dependence receptors. PLoS One 2007; 2(5): e463.

[74] Stilo R, Leonardi A, Formisano L, Di Jeso B, Vito P, Liguoro D. TUCAN/CARDINAL and DRAL participate in a common pathway for modulation of NF-kappaB activation. FEBS Lett 2002; 521(13): 165-9.

[75] Papa S, Bubici C, Zazzeroni F, et al. The NF-kappaB-mediated control of the JNK cascade in the antagonism of programmed cell death in health and disease. Cell Death Differ 2006; 13(5): 712-29.

[76] Johannessen M, Moller S, Hansen T, Moens U, Van Ghelue M. The multifunctional roles of the four-and-a-half-LIM only protein FHL2. Cell Mol Life Sci 2006; 63(3): 268-84.

[77] Maetzel D, Denzel S, Mack B, et al. Nuclear signalling by tumourassociated antigen EpCAM. Nat Cell Biol 2009; 11(2): 162-71.

[78] Scholl FA, McLoughlin P, Ehler E, de Giovanni C, Schafer BW. DRAL is a p53-responsive gene whose four and a half LIM domain protein product induces apoptosis. J Cell Biol 2000; 151(3): 495506.

[79] Bai S, Zha J, Zhao H, Ross FP, Teitelbaum SL. Tumor necrosis factor receptor-associated factor 6 is an intranuclear transcriptional coactivator in osteoclasts. J Biol Chem 2008; 283(45): 30861-7.

[80] Sorrentino A, Thakur N, Grimsby S, et al. The type I TGF-beta receptor engages TRAF6 to activate TAK1 in a receptor kinaseindependent manner. Nat Cell Biol 2008; 10(10): 1199-207.

[81] Yamashita M, Fatyol K, Jin C, Wang X, Liu Z, Zhang YE. TRAF6 mediates Smad-independent activation of JNK and p38 by TGFbeta. Mol Cell 2008; 31(6): 918-24

[82] Tanaka Y, Kobayashi H, Suzuki M, Kanayama N, Terao T. Transforming growth factor-betal-dependent urokinase upregulation and promotion of invasion are involved in Src-MAPKdependent signalling in human ovarian cancer cells. J Biol Chem 2004; 279(10): 8567-76.

[83] Wong BR, Besser D, Kim N, et al. TRANCE, a TNF family member, activates Akt/PKB through a signalling complex involving TRAF6 and c-Src. Mol Cell 1999; 4(6): 1041-9.

[84] Duronio V. The life of a cell: apoptosis regulation by the PI3K/PKB pathway. Biochem J 2008; 415(3): 333-44.

[85] Yang Y, Hou H, Haller EM, Nicosia SV, Bai W. Suppression of FOXO1 activity by FHL2 through SIRT1-mediated deacetylation. EMBO J 2005; 24(5): 1021-32.

[86] Ding L, Wang Z, Yan J, et al. Human four-and-a-half LIM family members suppress tumor cell growth through a TGF-beta-like signalling pathway. J Clin Invest 2009; 119(2): 349-61.

[87] Park J, Will C, Martin B, et al. Deficiency in the LIM-only protein FHL2 impairs assembly of extracellular matrix proteins. FASEB J 2008; 22(7): 2508-20.

[88] Pathan N, Marusawa H, Krajewska M, et al. TUCAN, an antiapoptotic caspase-associated recruitment domain family protein overexpressed in cancer. J Biol Chem 2001; 276(34): 32220-9.

[89] Yamamoto M, Torigoe T, Kamiguchi K, et al. A novel isoform of TUCAN is overexpressed in human cancer tissues and suppresses both caspase-8- and caspase-9-mediated apoptosis. Cancer Res 2005; 65(19): 8706-14.

[90] Razmara M, Srinivasula SM, Wang L, et al. CARD-8 protein, a new CARD family member that regulates caspase- 1 activation and apoptosis. J Biol Chem 2002; 277(16): 13952-8.

[91] Franchi L, Warner N, Viani K, Nunez G. Function of Nod-like receptors in microbial recognition and host defense. Immunol Rev 2009; 227(1): 106-28.

[92] Martinon F, Mayor A, Tschopp J. The inflammasomes: guardians of the body. Annu Rev Immunol 2009; 27: 229-65.

[93] Bergsbaken T, Fink SL, Cookson BT. Pyroptosis: host cell death and inflammation. Nat Rev Microbiol 2009; 7(2): 99-109.
[94] Ludwiczek O, Vannier E, Moschen A, et al. Impaired counterregulation of interleukin-1 by the soluble IL-1 receptor type II in patients with chronic liver disease. Scand J Gastroenterol 2008; 43(11): 1360-5.

[95] Verstrepen L, Bekaert T, Chau TL, Tavernier J, Chariot A, Beyaert R. TLR-4, IL-1R and TNF-R signalling to NF-kappaB: variations on a common theme. Cell Mol Life Sci 2008; 65(19): 2964-78.

[96] Bruey JM, Bruey-Sedano N, Luciano F, et al. Bcl-2 and Bcl-XL regulate proinflammatory caspase-1 activation by interaction with NALP1. Cell 2007; 129(1): 45-56.

[97] Chu ZL, Pio F, Xie Z, et al. A novel enhancer of the Apaf1 apoptosome involved in cytochrome c-dependent caspase activation and apoptosis. J Biol Chem 2001; 276(12): 9239-45.

[98] Aoto K, Nishimura T, Eto K, Motoyama J. Mouse GLI3 regulates Fgf8 expression and apoptosis in the developing neural tube, face, and limb bud. Dev Biol 2002; 251(2): 320-32.

[99] Bastida MF, Delgado MD, Wang B, Fallon JF, Fernandez-Teran M, Ros MA. Levels of Gli3 repressor correlate with Bmp4 expression and apoptosis during limb development. Dev Dyn 2004; 231(1): 148-60.

[100] Fukuda N, Saitoh M, Kobayashi N, Miyazono K. Execution of BMP-4-induced apoptosis by p53-dependent ER dysfunction in myeloma and B-cell hybridoma cells. Oncogene 2006; 25(25): 3509-17.

[101] Ohgushi M, Kuroki S, Fukamachi H, et al. Transforming growth factor beta-dependent sequential activation of Smad, Bim, and caspase-9 mediates physiological apoptosis in gastric epithelial cells. Mol Cell Biol 2005; 25(22): 10017-28.

[102] Kawai S, Sugiura T. Characterization of human bone morphogenetic protein (BMP)-4 and -7 gene promoters: activation of BMP promoters by Gli, a sonic hedgehog mediator. Bone 2001; 29(1): 54-61.

[103] Merino R, Rodriguez-Leon J, Macias D, Ganan Y, Economides AN, Hurle JM. The BMP antagonist Gremlin regulates outgrowth, chondrogenesis and programmed cell death in the developing limb. Development 1999; 126(23): 5515-22.

[104] Beenken A, Mohammadi M. The FGF family: biology, pathophysiology and therapy. Nat Rev Drug Discov 2009; 8(3): 235-53.

[105] Pajni-Underwood S, Wilson CP, Elder C, Mishina Y, Lewandoski M. BMP signals control limb bud interdigital programmed cell death by regulating FGF signalling. Development 2007; 134(12): 2359-68.

[106] Montero JA, Ganan Y, Macias D, et al. Role of FGFs in the control of programmed cell death during limb development. Development 2001; 128(11): 2075-84

[107] Moon AM, Capecchi MR. Fgf8 is required for outgrowth and patterning of the limbs. Nat Genet 2000; 26(4): 455-9.

[108] Sun X, Mariani FV, Martin GR. Functions of FGF signalling from the apical ectodermal ridge in limb development. Nature 2002; 418(6897): 501-8.

[109] Grieshammer U, Cebrian C, Ilagan R, Meyers E, Herzlinger D, Martin GR. FGF8 is required for cell survival at distinct stages of nephrogenesis and for regulation of gene expression in nascent nephrons. Development 2005; 132(17): 3847-57.

[110] Perantoni AO, Timofeeva O, Naillat F, et al. Inactivation of FGF8 in early mesoderm reveals an essential role in kidney development. Development 2005; 132(17): 3859-71.

[111] Chi CL, Martinez S, Wurst W, Martin GR. The isthmic organizer signal FGF8 is required for cell survival in the prospective midbrain and cerebellum. Development 2003; 130(12): 2633-44.

[112] Storm EE, Rubenstein JL, Martin GR. Dosage of Fgf8 determines whether cell survival is positively or negatively regulated in the developing forebrain. Proc Natl Acad Sci USA 2003; 100(4): 175762.

[113] Dailey L, Ambrosetti D, Mansukhani A, Basilico C. Mechanisms underlying differential responses to FGF signalling. Cytokine Growth Factor Rev 2005; 16(2): 233-47.

[114] Schmierer B, Hill CS. TGFbeta-SMAD signal transduction: molecular specificity and functional flexibility. Nat Rev Mol Cell Biol 2007; 8(12): 970-82.

[115] Yang YA, Zhang GM, Feigenbaum L, Zhang YE. Smad3 reduces susceptibility to hepatocarcinoma by sensitizing hepatocytes to apoptosis through downregulation of Bcl-2. Cancer Cell 2006; 9(6): 445-57. 
[116] Wildey GM, Patil S, Howe PH. Smad3 potentiates transforming growth factor beta (TGFbeta )-induced apoptosis and expression of the BH3-only protein Bim in WEHI 231 B lymphocytes. J Biol Chem 2003; 278(20): 18069-77.

[117] Dhanasekaran DN, Reddy EP. JNK signalling in apoptosis. Oncogene 2008; 27(48): 6245-51.
[118] Wagner EF, Nebreda AR. Signal integration by JNK and p38 MAPK pathways in cancer development. Nat Rev Cancer 2009; 9(8): 537-49.

[119] Aikin RA, Ayers KL, Therond PP. The role of kinases in the Hedgehog signalling pathway. EMBO Rep 2008; 9(4): 330-6.

(C) Mark Ditzel; Licensee Bentham Open.

This is an open access article licensed under the terms of the Creative Commons Attribution Non-Commercial License (http://creativecommons.org/licenses/by$\mathrm{nc} / 3.0 /$ ) which permits unrestricted, non-commercial use, distribution and reproduction in any medium, provided the work is properly cited. 